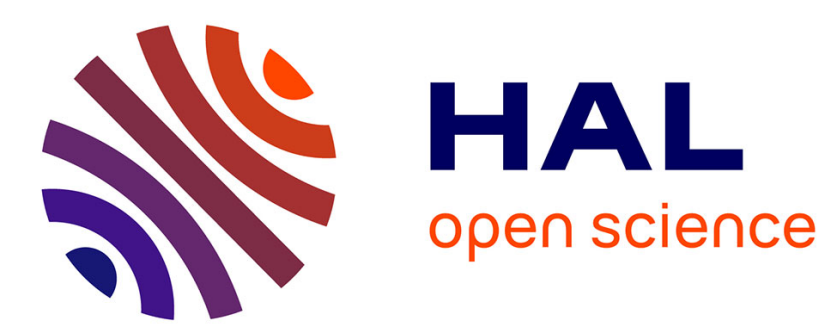

\title{
The Rule of Non-Opposition. Opening Up Decision-Making by Consensus
}

Philippe Urfalino

\section{To cite this version:}

Philippe Urfalino. The Rule of Non-Opposition. Opening Up Decision-Making by Consensus. Journal of Political Philosophy, 2014. hal-01226344

HAL Id: hal-01226344

https://hal.science/hal-01226344

Submitted on 11 Nov 2015

HAL is a multi-disciplinary open access archive for the deposit and dissemination of scientific research documents, whether they are published or not. The documents may come from teaching and research institutions in France or abroad, or from public or private research centers.
L'archive ouverte pluridisciplinaire HAL, est destinée au dépôt et à la diffusion de documents scientifiques de niveau recherche, publiés ou non, émanant des établissements d'enseignement et de recherche français ou étrangers, des laboratoires publics ou privés. 


\section{The Rule of Non-Opposition.}

\section{Opening Up Decision-Making by Consensus ${ }^{1}$}

[The last version of this paper has been published in the Journal of Political Pbilosopby, Vol. 22,

$n^{\circ} 3,2014$, p. 320-341]

Philippe Urfalino

The term "decision by consensus" is well-known. Participants and observers of collective decision-making use it for referring to processes of decision-making in very different contexts. The prevalence or the occurrence of some kind of consensus is observed in the decision processes of tribes, villages or small communities, of political assemblies, international organizations and expert committees to name but a few. Studies by ethnologists and historians attest that this decision-making practice, which they designate as either "consensus" or "unanimity", has long been in existence on all continents. It is the only decision-making mode mentioned for hunter-gatherer societies ${ }^{2}$ and it was the unique form of legitimate collective decision-making in village communities in Kabylia, in Ethiopia, in sub-Saharan Africa, in India, in Vietnam and in Japan ${ }^{3}$. It is not uncommon for groups of radical protesters to reject majority voting, which is the dominant practice within political parties and trade unions. In the United States, for example, several movements in defense of civic rights reject majority rule and use what they call decision by consensus ${ }^{4}$. The same way of deciding has been privileged by the global justice movement ${ }^{5}$. Since the 1960 's, a number of authors have observed a trend towards the use of decision by consensus in international fora. Barry Buzan counted about fifteen committees, councils, and conferences using the rule at the beginning of the $1980^{\prime} \mathrm{s}^{6}$. 
Among them, one can quote several committees of the United Nations. I will quote later some examples of decisions by consensus in expert committees and even in a constitutional court ${ }^{7}$.

While "decision by consensus" seems to be widespread in almost all kinds of deliberative bodies, what exactly this term designates is not very clear. It is often seen as an informal use of the unanimity rule or detected where the absence of voting procedure is observed. But the informality and the absence of a well-known procedure are negative specifications and leave the phenomenon loosely qualified. We are not sure that the use of this term refers to one and only one clearly identified kind of decision-making procedure.

The objective of this article is to propose a precise characterization of the collective practice behind at least an important part of the phenomena named "decision by consensus". The need for a clarification comes first from the frequency of this practice observed in human societies. Second, it comes from a normative reason: the practice of decision by consensus tends to be considered by social movements as being more democratic than the majority rule and its democratic character has been emphasized by some authors in democratic theory ${ }^{8}$. Hence, if we are to assess the benefit of "decision by consensus" we need to know the exact nature of this particular practice.

Indeed, should we wish to isolate a class of phenomena in order to study its conditions and proprieties, we need positive and conceptual criteria for defining its class. But first of all we need good case studies allowing a secondary analysis. Hopefully, it is possible to collect a set of rich descriptions of collective decision situations, scattered in different academic literatures, allowing to state that at least an important subset of what is usually called decision by consensus is indeed understandable as the use of a specific rule of decision. I will name it "rule of non-opposition”. By this rule, a participant of a meeting discussing a particular matter, advances a proposition for a decision to be made. In the case of an absence of contestation or 
counter-propositions, this proposition is considered as accepted and obtains the status of a decision made.

I don't assert that the various decision-making processes called "decision by consensus" can be qualified as the use of this rule. Some are in fact voting with quasi unanimity rule? others combine the rule of non-opposition and a complementary rule ${ }^{10}$, and it is possible that some belong to a still different class of phenomena. However, I will put forth some arguments in favor of the idea that the prevalence of this rule of non-opposition in several kinds of deliberative bodies has been overlooked.

The paper proceeds as follows. First, I provide descriptions of the use of this rule, and give a definition of the non-opposition rule, both as a specific sequence of acts and as a stopping rule. Second, I challenge the usual way of understanding the non-opposition rule by contrast with voting, stating that the contrast between logic of approval and logic of consent also has to be taken into account. Third, I examine the conditions of its use. The nonopposition rule satisfies groups whose concern is to decide without dividing. Finally, from the analytic benefit of opening up decision by consensus as the use of the non-opposition rule, I will examine, in a fourth part, whether consensus in decision-making is as democratic a procedure as is sometimes thought.

\section{I- The Rule Behind the Consensus Decision}

In this first part, I use five examples of case studies for proposing a positive definition of the non-opposition rule. By comparison with other procedures, I describe the specific way this rule determines the stopping of the decision process; and by comparing it to different sequences of non-opposition, I specify how such a sequence could constitute a rule.

\section{A. Five Remarkable Descriptions}


1. While observing collective decision-making processes in rural Sudan ${ }^{11}$ in 1970 and 1971, Sherif El-Hakim noted two particular features that characterize the process: First, that every male villager has the right to take part in the decisions. Second, that powerful or influential individuals enjoy a specific status in the discussion. Moreover, the initiative to call for a meeting aiming at making a collective decision is only accepted if coming from the most influential villagers. Indeed, village meetings tend to be frequent and long. A notable gives a lengthy presentation of the purpose of the meeting. After his talk, many others speak up, some expressing their opinion to a group talking nearby them, others calling out and gesticulating to attract the attention of the group at large. After a stretch of time, silence falls to allow the group to listen to another man. The new speaker presents what seems to him the consensus that has come out of the precedent discussion. The meeting can then evolve in any of the three following directions:

— In the case that the proposed statement is received even by the slightest signs of acquiescence and nothing comes along to complicate matters, that statement is thereby accepted as collective decision and the meeting is ended. This is the case even if only one or two participants manifest support for the statement while the others remain silent.

— In the case of disagreement, counter-proposals are advanced, working towards modifying the initial statement. These counter-proposals have sometimes little to do with the issue under discussion, but are understood and accepted as indirect expressions of disagreement and function as a mean to change it. At this point the discussions restart until another proposal, understood to offer a new definition of the consensus, is put forth in the same way as the first one was. If, as time passes, no new proposals emerge, or if those that do are in turn rejected, the meeting comes to an end without a decision being made. 
- In the rare cases where a proposition for a collective decision is explicitly contested, the meeting is broken off by invective and general agitation.

2. In her observations of decision-making processes in a community of fisherman on a small island of the west coast of Sweden, made in 1967 and 1968, Barbara Yngvesson remarks on the same absence of perceptible counting of preferences, and of formal rules for aggregating views $^{12}$. On board the fishing boats as well as in the assembly serving as the island's political body, collective decisions are made with the same protocol. For example, when an important decision must be made during a fishing expedition, such as changing fishing location, it is important that the decision be collective and not unilaterally imposed by the boat owner or any single crewmember. The process is three-fold: one of the fishermen suggests moving to thus and such other location; during the following half an hour at least the others may express reactions to this proposal; in the case of no counter-proposal, the first speaker reiterates his proposal and the boat heads for the designated fishing area. Island council meetings follow the same three-steps process, on the basis of proposals made by the presiding member.

3. The third and well-documented example is taken from a meticulous systematic study of decision-making in a Swiss political party in the canton of Berne. Using interviews, observation, and document analysis, Steiner and Dorff followed 111 party meetings from January 1969 to September $1970^{13}$. They observed 466 decision-making situations resulting from disagreement about what action to take. The researchers had posited that these disagreements would be settled in one of three ways: a majority vote; formation of an explicit oral agreement after the partisans of one option had clearly rallied to the other; or nondecision. As it turned out, $37 \%$ of the 466 cases fit into none of the three categories. The authors discovered that the non-categorized cases represented a fourth type, characterized by the following sequence: after time spent debating, a group member presented the conclusions 
he saw the debate leading to; if no one disagreed with this interpretation, it became the decision.

4. The General Agreement on Tariffs and Trade (GATT) decisions were not made by consensus at the outset. The GAT'T 1947 rules provided for voting. Each country was to have one vote, and different majority thresholds for approval were required for different types of actions. But very soon, practice diverged from the formal rules, and from at least 1953 the GATT used the method of consensus. From 1959, almost all its decisions were made by consensus. When the World Trade Organization (WTO) was created, this mode of decision was adopted as the formally preferred method. Article IX of the Agreement Establishing the WTO requires that only "where a decision cannot be arrived at by consensus, the matter shall be decided by voting". Steinberg describes the decision-making process as follows:

"In all plenary meetings of sovereign equality organizations, diplomats fully respect the right of any member state to: attend; intervene; make a motion; take initiative (raise an issue); introduce, withdraw, or reintroduce a proposal (a legal text for decision) or amendment; and block the consensus or unanimous support required for action. A consensus decision requires no manifested opposition to a motion by any member present. If an empowered state representative fails to object (...) to a draft at a formal meeting where it is considered, that state may be subjected to an argument that it is stopped by acquiescence from any subsequent objection to the draft" $"$.

5. At any given time between its inception in 1978 and 2000, the French committee for pharmaceutical drug approval was made up of approximately 30 members including a chairman, all appointed by the health administration for three-year renewable terms. During this period, with rare exceptions, voting was rejected. Direct observation of how the French 
drug approval committee proceeds (rather than interviewee answers) gives insight in the nature of this decision-making mode:

Once the non-member reporters have left the room, committee deliberation begins with the purpose of reaching a decision. After an exchange of views on the application at hand as a whole and the most debatable points in its-i.e., points likely to elicit alternative responsesdiscussion takes off from a proposal by the committee chair running the meeting. Some features of that proposal elicit reactions, expressions of disagreement or doubt, specifications, suggested additions. The arguments presented in support of the reactions are then discussed by the chairman himself or other members. The chairman then makes another proposal which is meant to be a synthesis of the preceding discussion. That second proposal may again elicit partial objections, or suggestions of ways to improve it. Discussion progresses thus, punctuated and pushed forward by the chair's successive proposals. The chairman's proposal acquires the status of a decision made when it appears that none of the participants has any more objections to make. It should be noted that when the chair calls for reactions to what will soon become his last proposal, some participants overtly approve but most abstain from openly expressing their opinion in any way ${ }^{15}$.

\section{B. A Specific Sequence of Acts}

These five studies concern collective decisions, each in different societies and institutional contexts: a village in Sudan, a fishing community in Sweden, a political party in Switzerland, an international organization, and a French committee of experts. There is a tendency to characterize this mode of decision in contrast with voting. This is what El-Hakim, Steiner and Dorff, Ingvesson, Steinberg and Urfalino all did. The contrast is clear and insightful: In the five descriptions given above, there is no systematic expression of the preferences of participants, no counting of their opinions, and thus there is a possible 
ignorance of the distribution of these opinions at the end of the process. Another common observation is that each participant possesses veto power since he/she can contest the proposal and thereby prevent it from becoming the decision. This veto power associated with the absence of voting gives weight to the idea that this decision-making process is in fact an informal procedure of unanimity. And it is, I guess, the reason of the widespread use of the expression "decision by consensus": consensus is used by default because the absence of voting forbids to name that procedure unanimity rule. It is a quasi-unanimity rule, unanimity being deduced if veto power has not been exercised.

This first characterization is not incorrect but combines negative features (no voting, no counting of expressed preferences) and positives features (the occurrence of a proposal, the absence of opposition, veto power). For getting a clear characterization of the decision process we must avoid a description and a definition by default. We need to be able to give a solely positive description as a series of acts. From the five descriptions above, we can note several common features designing a specific sequence of acts that may be used to recognize this mode of decision. This sequence gives us a positive description.

1) After various ways of presenting the issue requiring a decision, and of deliberating and/or bargaining before or during the meeting, a member of the assembly, most often a chairman or a member with a certain degree of authority, makes a public proposal for a possible decision. 2) This declaration opens two possibilities: a) no one speaks out against the proposal just presented, in which case, even if most participants remain silent and only a few explicitly manifest their approval, that proposal becomes the decision; or b) at least one participant explicitly or implicitly contests the proposal, in which case the consultation process has to restart in the same or in another meeting until a new proposal is made, which once again gives rise to alternatives a) or b); 3) if all successive proposals are contested, the decision- 
making process for that particular matter is postponed indefinitely or another rule of decision has to be used.

Hence, this decision-making mode can be characterized as follows: at the end of a deliberative session or a series of discussions, a decision is made when all present collectively note — during a moment of pending acutely felt by all—an absence: the absence of any overt opposition to the proposition at hand. This is the reason why this rule can be named nonopposition rule $e^{16}$. The use of the expression "decision by consensus" manifests the influence of the voting model on our comprehension of the rules of collective decision-making, because it is only in the case of voting that the ending of the decision-making process is indexed on a proven distribution of opinions. By contrast, the rule of non-opposition is not directly based on such a distribution.

We must finally check whether the succession of proposals and the absence of opposition could be elevated to the status of a rule.

\section{Status of a Decision Mode: Coup, Device, and Rule}

The non-opposition rule can be regarded as a rule of group decision just as, for example, majority voting. But it has characteristics which partly explain the fact that it was often taken for an informal unanimity rule: it does not use any technique or device and it does not mobilize any artifact external to the wills of the participants. It does not use any technique channeling the expression of the opinions of the participants, like the vote does; and the outcome of the decision depends on the will of each participant, likely or not to contest the proposal; it does not result from a counting of voices which opposes to the opinion of each one, as an external fact, the aggregation of all the other opinions.

These characteristics cannot be qualified as "informal" as, indeed, informal phenomena, in the sense of having no form, do not exist. We have resorted to this adjective when we do 
not know how to qualify a phenomenon, except in a negative way, by contrast or resemblance with another one which we know better how to describe ${ }^{17}$.

The rule of non-opposition can be described and recognized by a sequence of acts which can be given the status of a rule. But the same sequence of acts can occur without always having the status of a rule. Such is the case of the successive acts which characterize decision by non-opposition. This succession can correspond to the use of a recognized rule of decision, but also to situations whose status is less clear: it can indicate the occurrence of a coup; it can also be used like a process tolerated by all the participants for its convenience. Here are some examples.

A Coup

The first example is taken from a study of the Fonds Régionaux d'Art Contemporain or FRAC, région-level art-purchasing commissions created in France in 1982 [the région is a political and administrative unit]. FRAC administrative boards were called upon to accept or reject an expert committee's proposals for purchasing contemporary art works. In some of the regions, the majority of elected officials on the administrative board were hostile to the experts' choice of art works, disconcerting for neophytes. But FRAC administrative board presidents, in many instances important regional political figures, were generally inclined to follow the experts' recommendations, less by artistic taste than because they expected that the international-level art collection the experts meant to develop would enhance their region's renown. In one of the three regions studied, after the works had been presented and at precisely the moment one might have expected the matter to be put to a vote, the FRAC president would address his fellow board members firmly in the following terms: "My friends, you've heard what the experts have to say — these works are of very high quality. We're not really going to vote now, are we? I propose we take them all—do you agree?" Elected officials who were reluctant to buy 
did not dare oppose the region's rising politician, so the president got the art works bought without a vote and without expression of any disagreement. Still, he was careful not to incur sudden rejection of his stratagem, and if he felt there was strong opposition to a given work, or if one of his advisors sensed this, he let that one be pulled from the $\operatorname{lot}^{18}$.

This example shows a hybrid situation. It is at first a clear institutional situation where a collective decision has to be made by an official deliberating body, but finally the purchase decision is obtained by a stratagem mixing proposition and intimidation which cannot be regarded as a rule of decision.

An Accepted Device

For four years I observed, as a member, the functioning of a section of the National Committee for Scientific Research (CNRS) in France. Each section, composed of approximately twenty elected and appointed members, was in charge of evaluating research centers and researchers of the CNRS. All the collective decisions that this section was called on were made with voting machines and by majority rule. However, some presumably unimportant decisions that seemed to elicit ready convergence of opinions were made differently. This was the case for decisions on procedure, the clearest example of which is choosing the moment the assembly can stop debating the issue and put it to a vote. After long discussion, the section president might declare: 'Dear colleagues, it seems to me we've debated long enough. I propose we put the matter to a vote." If no one contested that invitation, it became the decision and we proceeded to vote. Two or three times, the length of the discussion time itself was the focus of a long disagreement, and at that point the section president proposed that the assembly vote to determine the balance between those who wanted to keep debating and those who wanted to vote-i.e., we voted to determine whether or not to vote. It should be noted, however, that in such voting to the second power as it were, the 
decision to vote to decide whether or not to vote was made by non-opposition! Here we have touched on a sort of logical limit to electoral formalism: to escape infinite regression and be able to decide collectively whether or not to move to a vote, the group needs a decision-making mode other than voting ${ }^{19}$.

Steiner and Dorff's study of a Swiss political party, already mentioned, presents a case where the use of what they call decision by interpretation is close to the status of a device. But because it is not reserved to procedural issues, it is a kind of second-best rule of decision used when none of the parties deems that voting and majority rule would give them a better result.

In a coup, like in the FRAC case, the use of non-opposition to a proposal for obtaining a decision is a pseudo-collective decision, with weak legitimacy. It has no more stability than the one embedded in the inequality of resources, thus providing the possibility of intimidation. As a device or second best rule, like in the CNRS case and the Swiss political party, nonopposition is considered less legitimate than voting. And it is likely to be rejected in favor of voting when there is a great deal at stake and the assembly is sharply divided. Keeping in mind that any participant in all the above cases can rightfully call for a vote, we may say that nonopposition as device is preferred to other options in two types of situations:1) when it seems a way of speeding up a decision-making process that seems headed for a decision understood to comply with the wishes of the majority; 2) when it seems to represent a balance between the expectations of the person proposing a consensus interpretation in the hope that it will not be contested and the expectations of participants who, even though they are opposed to that interpretation, prefer not to speak up because they feel fairly certain they are in the minority and do not want that minority status revealed. 
But the sequence of action, the observation of non-opposition after a proposal has been made, could be an actual rule of decision ${ }^{20}$, as seen with four of the five cases described in the first part. It could be the only rule used in a group for making decision, sometimes the only one known, or the rule preferred to the use of voting and of a majority threshold. When the sequence is an authentic stopping rule of decision, it implies for the participants three dimensions, technical, phenomenological and normative. First, following the rule is a way for stopping the decision process. Second, for each participant, the rule organizes what he/she can expect without hesitation or doubt: That when a proposal has been put forth and is not challenged, for a defined lapse of time, the participants know that a decision has been reached and its content is the proposal. Third, it is clear for all participants that this is a legitimate way for making a decision ${ }^{21}$.

\section{II- The Principle of the Rule: the Logic of Consent}

In defining the rule of non-opposition we have rejected a definition by default of decision by consensus: it is not unanimity rule without voting. But we have nevertheless to think about the proximity between non-opposition rule and unanimity rule, the common feature being the veto power given to each participant. I shall state in this part that the relevant contrast for thinking about it is not only the contrast between voting and non-voting but also the contrast between two principles.

\section{A. The Logic of Consent and The Logic of Approval}

We can consider a situation of a decision where a proposal P (an option for an action, a motion, a candidate) has to be approved or rejected. The decision is comparable to the question: do you approve the proposal P? The collective answer will be either Yes or No. The range of the individual answers is broader: Yes, No, Abstain. 
The logic of approval and that of consent differ by the register of the possible expressions, the status of the divergences between opinions and the expected ending.

Register of expressions. With the logic of approval, which for example is observable in the use of voting associated with majority rule, the participants in the decision have the choice between two opposed expressions, an expression of approval or disapproval. The possible abstentions decrease the number of the opinions weighing on the result, because they contribute neither to the rejection nor to the adoption of the proposal P.

On the other hand, in a decision by non-opposition, which we observed for example in the case of the assembly of the Sudanese village, the line of fracture is not between Yes and No. The line of fracture is between, on the one hand, disapproval of the stated proposal and, on the other hand, the set made up of approvals and absences of expression meaning nonopposition to the proposal.

It is remarkable that explicit approval does not have in this case more impact than silence or the absence of expression, corresponding to a kind of abstention. From a functional point of view, insofar as the stopping rule is the noting of an absence of opposition, the true line of fracture is between the disapproval and the non-disapproval. The abstentions, as approvals, still contribute to the adoption of the proposal P. Plus, the abstention from all is sufficient to lead to the adoption of $\mathrm{P}$. It is important to notice that, in the case of the logic of consent, the double negation is not equivalent exactly to an assertion: not to disapprove does not correspond exactly to an approval, but amounts to accepting that the group decision is the proposal.

By doing this, the two logics use the three types of possible reactions of one person to a proposal made by another one:

- Approving $\mathrm{X}$ is to be in favor of $\mathrm{X} /$ Disapproving $\mathrm{X}$ is to be against $\mathrm{X}$. 


\section{- Consenting to $\mathrm{X}$ is to be not against $\mathrm{X}$.}

The status of the divergences of expressed opinions. In the logic of approval, Yes and No are clearly in competition. The respective value of the gathering of their partisans must be evaluated and compared; one will override the other. In the logic of consent, one does not escape, of course, the alternatives of rejection or validation of the proposal; however disapproval and non-disapproval are not destined to express the opposition of two opposite trends of public opinion. It so happens that this opposition exists but must subside, at least with regard to the explicit expression of the opinions, so that a decision becomes possible. The occurrence of only one opposition is enough to disallow the proposal, but it opens up the search for another proposal which will not cause opposition any more.

The expected ending. Finally, the expected ending of the logic of consent is unanimity, at least in appearance. On the other hand, the logic of approval leads to the emergence of a majority for or against the proposal P.

\begin{tabular}{|l|l|l|l|}
\hline & Register of Expressions & Status of Divergences of the Expressed Opinions & The Expected End \\
\hline Logic of & Yes and No & Explicit competition & A majority imposes its \\
appoint of view \\
\hline Logic of & No and Abstain (with & The contestation of the proposal manifests an & Apparent unanimity \\
& some explicit approvals) & opposition which must be overcome & \\
\hline
\end{tabular}

The distribution of the use of these two logics does not correspond exactly to the partition between the modes of decisions implying voting and those which do not. Logic of consent is not limited to assemblies which do not practice voting. Indeed, it can also occur in assemblies that do. One finds examples in certain international organizations where the official rule of decision is unanimity. It is in particular the case of the Security Council of the United 
Nations, at least for its permanent members. This case deserves some attention because it helps to grasp the spirit of the decision by non-opposition.

\section{B. Apparent Unanimity, Veto and Abstention}

Decision by non-opposition bears a resemblance with the exercise of unanimity rule in certain international organizations. The most famous case and also the most interesting is that of the Security Council of the United Nations. This council includes five permanent members and ten non-permanent members. Its decisions are made by a show of hands. The nonprocedural decisions comply with a double rule of decision, the unanimity of the college of the permanent members and a supermajority 9 out of 15 for the whole of the Council. The rule was fixed by paragraph 3 of article 27 of the Charter of the United Nations: "Decisions of the Security Council on all other matters [than procedural] shall be made by an affirmative vote of nine members including the concurring votes of the permanent members". Thus the text grants a veto power to the five States which have permanent representatives (the United States, Russia, China, United Kingdom and France) and the whole of their affirmative votes seems to be necessary. But in practice, since 1946, the permanent members sometimes abstain and some non-procedural decisions are made with the required supermajority of the members of the council, but without the unanimous agreement of the permanent representatives ${ }^{22}$. The most remarkable case is that of resolution 202 (65), which was concerned with Southern Rhodesia. It was adopted on May 6, 1965 by a vote of 7 to none, with 4 abstentions, the abstainers being four of the five permanent members ${ }^{23}$. The decision had thus been obtained with only one affirmative vote within the college of the permanent members. The issue of the validity of the decisions taken with such abstentions was raised on several occasions, but finally this practice was continuously accepted without being officially recognized as a written rule. 
The States accept this practice which deviates from the text while wanting to keep it with the status of a tolerance ${ }^{24}$.

This example of the Security Council is particularly enlightening. It makes it possible to distinguish two components of the rule of unanimity which logic tends to confuse but which practice dissociates: the veto and the requirement of a complete convergence of the opinions. These two components have a remarkable consequence on the value of the expressed opinions. The expression of each participant can be considered from two different perspectives: the expression of his or her opinion and the effect of this expression on the group decision. Thus, if a participant disapproves of a proposal while he thinks that all other members approve of it, the expression of his disapproval would have two aspects: it would express his opinion against the option, and it would mobilize his veto power. However, a member can be opposed to a proposal while not wishing to block the collective decision ${ }^{25}$. In parallel, the other members see only advantages to a situation where this member can express in some way his disapproval, without blocking the collective decision. This explains that, within certain international organizations using unanimity rule, the abstention has acquired a specific status, that of a non-approval not being worth a veto.

By doing this, the emergence of a tolerance of the abstention dissociates the veto power and the requirement of unanimity. Whereas the rule of unanimity imposes in theory a mutually exclusive choice between the exercise of the veto and unanimous decisions, the practice adds the possibility of an apparent unanimity with abstention. So where the written rule is unanimity, it sometimes happens that what is actually required to obtain a decision is the absence of veto but not the need for an absolute convergence of opinions.

As the outcome of the two previous parts, we may associate the rule of non-opposition with a series of precise actions and distinguish it from other decision-making rules by two 
contrasts: not only voting processes versus non-voting processes, but also logic of approval versus logic of consent.

\section{III- Deciding Without Dividing}

We can now try to understand why some deliberative bodies use the non-opposition rule. From the descriptions we have collected, it seems that the prevalence of this rule is linked to a certain balance between the concern for not dividing the group and the need to go through with certain decisions. First, the non-opposition rule has the advantage of avoiding explicit loss of a minority, each participant having the possibility to block a proposal he/she doesn't want. Second, the need for decision could be satisfied despite the exercise of veto power, by the restriction of its effective use.

\section{A. The Advantages of Apparent Unanimity}

When a decision is reached by the non-opposition rule, the true distribution of the opinions is not always known by the participants. In any case, whatever the actual opinions are, their apparent distribution is unanimity. This apparent unanimity has advantages that bodies using this rule are looking for or are pleased to benefit from. This is the reason why, when they have the choice, they adopt or keep a rule which spares the group explicit division.

It has become commonplace, with good reason, to note that the majority rule can produce division. More precisely, if the opinions within a group are divergent, majority rule tends to highlight these divergences and to channel them in two opposed tendencies, one overriding the other. Its use thus supposes the capacity of the group to combine a procedure which brings to the fore its divergences and the maintenance of the cohesion which is necessary to its survival. The risk of division is noted by ethnologists who have stressed that 
strong dissensions within a village are likely to cause the departure of a part of its inhabitants who later may establish a new village ${ }^{26}$.

The visibility of competition can, in some cases, even cause violence. For example, in Sierra Leone, as in many African countries, elections were introduced when an independent state was formed on a Western model. But the competition involved in an election (for designating members of parliament or mayors) had an effect that everyone wanted to avoid. The losers and their followers were ridiculed, jostled and sneered at in ways that degenerated into physical violence. So the country began designating a single candidate using the traditional decision-making mode, palaver, which has the advantage of clearly identifying an option-here, a candidate-without a too much visible competition. The single candidate then wins the election without having to defeat anyone $\mathrm{else}^{27}$.

Political groups of protestors, at the margin of established political organizations, suffer from the same fragilities. Cohesion, participation and agreement benefit them because they reinforce solidarity within the movement. The division or the feeling of belonging to a minority excluded from any influence on decision-making within the group can cause defection, which these movements fear. "When people share ownership of decisions—activists frequently used that term—-their sense of solidarity and commitment is heightened. Movement organizations can offer people little in the way of selective incentives to participate, and the long-term rewards are often unclear. (...) The trouble with majority voting, say its critics, is that every decision made leaves losers in its wake. (...) Groups that put a premium on the possibility of consensus help that not to happen, thus generating solidarity benefits." ${ }^{28}$.

In committees of experts and constitutional courts, division can be feared, not to avoid defections, but for its external effect. In certain contexts, the value attached to the decisions of the committee can suffer from the visible disagreements between experts. Thus during the 
creation of the French committee for pharmaceutical drug approval, there were two defensive dimensions to this quest for a consensus that would reflect the opinion of the given scientific community: first, it was a response to the fear that the new arrangement might be contested by pharmaceutical firms and the medical milieu; second, collective discussion seemed the best means of collectively mobilizing recent knowledge and practices. Similarly, one of the reasons why the Italian Constitutional Court has favored apparent unanimity is the concern for the authority of its decisions in a political society that is strongly divided ${ }^{29}$.

\section{B. The Veto Restraint}

Decision by non-opposition provides veto power to each participant as one opposition is enough to reject a proposal. This brings to the fore the following question: how could decisions be reached in this context? We can expect that, quite often, some participants contest all the successive proposals made by the chairman. This rule could be expected to be exposed to systematic opposition and finally to be very fragile.

But indeed, as seen before, decision by non-opposition is observable in very different societies and contexts and with decisions for which the stakes are not negligible. The fact is that the rule is generally reputed to be time-consuming. For example, in societies using palaver, men spent a lot of time gathering information about each other's wishes and to discuss the issues at stake, and finally meetings take a long time to reach decisions. We can observe the same for the use of the non-opposition rule in social movements, as suggested in the title of Polletta's book, Freedom is an Endless Meeting. Nevertheless, even if they need time, decisions are made. How is this possible? Decision by non-opposition is made possible by the fact that participants consent not to oppose the last proposal. So the question is why they refrain from blocking the decision.

The literature proposes two types of responses to this question: negotiation and moral 
pressure. These two manners for moderating the use of veto power are not exclusive and could work together.

\section{Veto Refrained by the Way of Negotiation}

El-Hakim explains that, in the Sudanese village he studied, the reason why individuals who are opposed to a proposition put forth remain silent despite their opinion is to protect themselves from retaliation coming from the propositions' main partisans. He describes how notables use body language and voice intonations to express the degree of importance they attach to a particular decision. This indicates, in concrete terms, the degree to which participants opposed to a proposal that is supported by a notable in control of collective goods such as water distribution or the dispensary may fear that their position may be held against them when they next need those goods. But if members of the village have equivalent power resources and disagree, one of them can use his veto power against a proposal approved by the other and decisions on the issue at stake cannot be made. In this case, the changing of distribution of interests or of power resources, with time going, will allow the possibility of bargaining and, finally, of a decision being made. Based on this view, veto is the object of implicit negotiation and the possibility of making decision depends on an equilibrium of power resources that are relevant for participants and interests linked to the stake of the decision at hand $^{30}$.

This is the mechanism which is explicitly at work in international organizations using the rule of non-opposition. In such situations, there is no deliberation from which the proposals would come up. The team of the chairman or the organizers of the convention gives a framework for a final proposal, but mainly its elaboration proceeds progressively from multilateral negotiations. These negotiations combine an equal veto right for each nation with very unequal capacities to use this veto power. 
The case of the GATT and W'TO is highly instructive. In the early 1960s the consensus rule was introduced instead of majority voting. The change can be understood to have been implemented in the name of equality among the states, on the initiative of the richest among them. The rich states had realized that after decolonization, the total number of states had considerably increased and a coalition of developing countries could reduce them to minority. In the name of states' equality in collective decision-making, the richer countries introduced a decision-making rule that would preserve their influence. The veto power granted to each and all does not prevent inequality in resources from affecting pre-vote negotiations on the proposals to be submitted for agreement. Unlike countries with fully developed economies, small countries cannot reject commercial trade agreements which they would prefer more balanced but without which they cannot survive ${ }^{31}$.

More generally, the diffusion of the non-opposition rule in international organizations seems to be the result of a search for a compromise between the need for using a procedure keeping the idea of equal sovereignty of each state by the equal right of veto, and the need for negotiations reflecting the real weight of the nations ${ }^{32}$.

\section{Veto Refrained for Moral or Normative Reasons}

The second type of response emphasizes the normative dimension: at one point, dissent is regarded as unacceptable and provokes marks of disapproval. This dimension is clearly present in palaver, in social movements and in expert committees.

As Terray explains, the fact that palaver is considered by the actors involved as a search for the "right" solution to a problem, means that "as soon as the solution has manifested itself, debating stops; any further comment would be considered superfluous. The right solution is the one which is the most favorable to the community's well-being; it should therefore unanimously gain consent, and as soon as it has been voiced, anyone who thinks he can 
continue to oppose it reveals by this very opposition that he prefers his personal interest to the general interest" 33 . One would like to know how it is that participants feel that the "right solution" has been proposed despite the persistence of disagreement. What indices allow them to conclude that objections up until then legitimate are now unwelcome?

Francesca Polletta noted that in political associations the requirement for consensus is not challenged by the obstinacy of some militants, as we could imagine from outside such social movements :

In a discussion with another group of DAN (Direct Action Network) activists, (...) I posed the question explicitly. Why do they trust that no one will tie up the discussion in tangential talk and that people will not hold on to selfish and stupid positions, even to the point of blocking a decision? David argues that the process itself, the orientation not to winning but to making the best decision, discourages that kind of obstructionism. Brooke points out that DAN has a set of principles that people are expected to uphold (...). Jeremy shrugs: "there's a commitment there. You see the same people week after week, and you think, "My god, you really do care about this"34.

The exercise of normative pressure in expert committees is more explicit. In the case of an expert committee and of a constitutional court, the opposition has to be an objection and it is not an unconditional veto. Participants can not only say that they approve or disapprove, they have to give reasons. Speaking out against the proposal constitutes an objection while it does not necessarily amount to a veto. In order for the objection to be a veto, it has to be accepted; that is, the other members have to deem it valid. Here, the context is one where deliberating members are not supposed to have any interests at stake and in most cases do not; they have nothing to negotiate and nothing to fear or hope from speaking out-except in connection with the value that will be attributed to what they say. Use of the option to contest 
a proposal is not conditioned here by any resource external to the decision-making process; rather, the value of contestation, its veto power, is conditioned by whether or not the arguments used against the proposal are recognized as valid. In this case, what compels consent is an exhaustion of acceptable objections: a person may still not be satisfied with the latest consensus proposal, formulated after a long debate and several objections, but can no longer oppose it, having no further arguments that would be judged appropriate in relation with the normative context and the rhetoric constraints at work in the assembly. Here decision by nonopposition is decision by exhaustion of objections ${ }^{35}$.

The veto restrain by the way of normative pressure is very close to Rousseau's thoughts about supermajority and unanimity. Following his point of view, the elector has to balance, on one hand, the concern for giving to the community the most useful opinion he could have about the issue at stake, and on the other hand, the concern for not blocking a decision needed for its welfare ${ }^{36}$.

\section{Is the Non-Opposition Rule Democratic?}

The purpose of this paper was not normative, but to identify a distinct rule of collective decision-making on the basis of a critical analysis of available descriptions. Nevertheless I cannot ignore the democratic value which has been attached to decision by consensus. A number of authors, in particular scholars who take special interest in the deliberative nature of democracy, have noted that decision by consensus is better suited to fulfill the need for a more equal participation in the debate ${ }^{37}$. A passage from Nelson Mandela's autobiography describing the proceedings of the local meetings that were held in the regent's house in Mqhekezweni has been quoted by several authors as a good example of the deliberative and participative virtue of the search for consensus ${ }^{38}$ : 
Everyone who wanted to speak did so. It was democracy in its purest form. There may have been a hierarchy of importance among the speakers, but everyone was heard, (...).

The foundation of self-government was that all men were free to voice their opinions and equal in their value as citizens. (...)

The meetings would continue until some kind of consensus was reached. They ended in unanimity or not at all. Unanimity, however, might be an agreement to disagree, to wait more propitious time to propose a solution. Democracy meant all men were to be heard, and a decision was taken together as a people. Majority rule was a foreign notion. A minority was not to be crushed by a majority.

Only at the end of the meeting, (...), would the regent speak. His purpose was to sum up what had been said and form some consensus among the diverse opinions. But no conclusion was forced on people. If no agreements could be reached, another meeting would be held 39 .

After the previous pages, the reader can recognize in this passage a good description of the use of the non-opposition rule!

Obviously, at this point, I cannot start a normative argumentation on the comparative virtue of decision rules. But I can only try to profit from the descriptions of collective decisions I gathered and analyzed in this text for giving, as a conclusive remark, an observation which should be taken into account in a normative argumentation about the democratic character of the non-opposition rule, of which use the palaver described by Mandela is a good example.

In palaver, as in other cases, the equal right to participate in the decision-making process should not conceal the inequality existing both in fact and by right in the weight of the various individual members when it comes to reaching a decision by the rule of non-opposition. Unlike voting, particularly with the majority rule, which ensures that each participant weighs as much as any other in the final result ${ }^{40}$, the non-opposition rule integrates specifically the fact that 
participants will not contribute equally to the decision. The formal equality of members in the participation of a debate does not rule out factual differences, sources of inequality of influence. Indeed, not only do such differences exist, but the inequality they reflect is deemed legitimate. This explains why these societies prefer the non-opposition rule to voting, when this latter technique is known to them and if confronted with a choice. The results of Terray's discussion of the respective merits of voting and palaver with members of the Abron society he studied, demonstrated their acute feeling that voters' equal degree of influence is unreasonable: "The idea that all votes are of equal weight seemed preposterous to them: there are intelligent men and imbeciles, old hands and greenhorns" ${ }^{\prime 1}$. The authors who stress the democratic character of palaver forget the end of Mandela's passage, partially quoted above, where he explains that he has always followed the principles he first saw demonstrated by the regent in the meetings:

I always remember the regent's axiom: a leader, he said, is like a shepherd. He stays behind the flock, letting the most nimble go on ahead, whereupon the others follow, not realizing that all along they are being directed from behind ${ }^{42}$.

The same understanding can be detected among members of the French committee for pharmaceutical approval. The experts in the commission accept as a ground rule that differences in their degree of competence (which varies constantly according to the matter at hand) should be reflected in the degree of influence each one has on the final decision ${ }^{43}$. Moreover, we have seen before how "decision by consensus" used in international organizations is congruent with the acceptance of the unequal weight of nations.

The various descriptions of the use of the non-opposition rule demonstrate that this rule integrates and puts to use a general acceptance of inequality in individual contributions in collective decision-making. The general equality of participation in the process coexists with a 
prevailing recognition of the legitimacy of unequal influence of individuals, depending on social status or expertise. In general, the possibility to express the intensity of preferences and the possibility to restrain veto by negotiation or by normative pressure contribute to the fact that the rule of non-opposition is not equalitarian. The influence of inequalities (in internal resources such as argumentation skills or the knowledge of the issues, as well as in external resources such as social and economic capital) is not bound by the rule of non-opposition, at least for the final determination of the decision ${ }^{44}$.

As a consequence, the democratic character of this rule of decision has to be weighted depending on whether we emphasize the equality of each with regard to participation in the debating process or the equal weight of each in the final result.

\section{$\underline{\text { References }}$}

Abélès, Marc. 1983. Les lieux du politique. Paris: Société d'ethnographie.

Baechler, Jean. 1994. Démocraties. Paris: Calmann-Lévy.

Bailey, Frederick George. 1965. Decisions by Consensus in Councils and Committees. Pp 1-20 in M. Banton (ed.), Political Systems and Distribution of Power, London: Tavistosck.

Buzan, Barry. 1981. Negotiating by Consensus: Developments in Technique at the United Nations Conference on the Law of the Sea, The American Journal of International Law, 75, 324-348.

Charney, Jonathan. 1978. United States Interest in a Convention on the Law of the Sea: The Case for Continuated Efforts. Vanderbilt Journal of Transnational Law, 11, 39-76. Cohen Joshua. 1989. Deliberation and Democratic Legitimacy. Pp 17-34, in A. Hamlin, Ph. Pettit (Eds). The Good Polity. Oxford: Blackwell. 
Coleman, James. 1990. Foundations of Social Theory. Cambridge: Harvard University Press.

Dumont, Louis. 1981. Homo Hierarchicus: The Caste System and its Implications, trans. Mark Sainsbury. Chicago : Chicago University Press.

El-Hakim, Sherif. 1978. The Structure and Dynamics of Consensus Decision-Making. Man, 13, $55-71$.

Elster, Jon. 2013. Security Against Misrule. Juries, Assemblies, Elections. Cambridge: Cambridge University Press.

Ferme, Mariane. 1998. The Violence of Numbers : Consensus, Competition and the Negociation of Disputes in Sierra Leone. Cahiers d'Etudes Africaines, 38, 555-580.

Fishkin, James. 1991. Democracy and Deliberation. New Haven: Yale University Press.

Fromont, Michel. 1961, L'abstention dans les votes au sein des organisations internationales. Annuaire français de droit international, 7, 492-523.

Graber, Frédéric. 2007. Obvious Decisions. Decision-Making among French Ponts-etChaussées Engineers around 1800. Social Studies of Science, 37, 935-960.

Gross, Léo. 1951. Voting in the Security Council : Abstention From Voting and Absence From Meeting. The Yale Law Journal, 60, 209-257.

Gross, Léo. 1968. Voting in the Security Council : Abstention in the Post-1965 Amendment Phase and Its Impact on Article 25 of the Charter. The American Journal of International Law, 62, 315-334.

Haug, Christoph. 2010. Discursive Decision-Making in Meetings of the Global Justice. Movements Cultures and Practices. Dissertation zur Erlangung des akademischen Grades Doktor der Philosophie (Dr. phil.) am Fachbereich Politik- und Sozialwissenschaften der Freien Universität, Berlin. 
Mahé, Alain. 2000. Les assemblées villageoises dans la Kabylie contemporaine. Etudes Rurales, 155-156, 179-212.

Mandela, Nelson. 1995. A Long Walk to Freedom. London: Abarus.

Martin, Pierre. 1998. Réconcilier délibération et égalité politique : Fishkin et le sondage délibératif. Revue Française de Science Politique, 48, 150-154.

Mansbridge Jane. 1980. Beyond adversary Democracy. New York: Basic Books.

May, Kenneth. 1952. A Set of Independent Necessary and Sufficient Conditions for Simple Majority Decision. Econometrica, 20, 680-684.

Novak, Stéphanie. 2013. The Silence of Ministers: Consensus and Blame Avoidance in the Council of the European Union. Journal of Common Market Studies, 51, 6, p. 10911107.

Nullmeier, Frank and Pritzlaff, Tanja. 2009. The implicit normativity of political practices. Analyzing the dynamics and power relations of committee decision-making. Critical Policy Studies. 3-4, 357-374.

Pasquino, Pasquale. 2007. Voter et délibérer. Revue Européenne des Sciences Sociales, 45, 35-45.

Polletta, Francesca. 2002. Freedom is an Endess Meeting. Democracy in American Social Movements, Chicago: University of Chicago Press.

Popkin, Samuel. 1979. The Rational Peasant. The Political Economy of Rural Society in Vietnam, London: University of California Press.

Rae, Douglas. 1969. Decision Rules and Individual Values in Constitutional Choice. American Political Science Review, 63, 40-56.

Robert, Henry Martyn. 1876-1915, Rules of Order for Deliberative Assemblies Revised, http://www.robertsrules.com/ 
Rousseau, Jean-Jacques. 2004. Considerations on the Government of Poland. Pp. 177-260 in J.J. Rousseau, The Social Contract and Other Later Political Writings, ed. and trans. Victor Gourevitch, Cambridge: Cambridge University Press.

Saalfeld, Thomas. 1995. On Dogs and Whips: Recorded Votes. p. 528-565 in H. Döring, Parliaments and Majority Rule in Western Europe, Mannheim: Martin's Press. Schwartzberg, Melissa. 2008. Voting the General Will. Rousseau on Decision Rules. Political Theory, 36, 403-423.

Sen, Amartya. 1999. Democracy as a Universal Value. Journal of Democracy, 10, 3-17.

Silberbauer, George. 1982. Political Process in G/wi bands. Pp. 23-36 in E. Leacock, R. Lee (eds), Politics and History in Band Societies, New York/Paris: Cambridge University Press/ed. de la Maison des sciences de l'homme.

Smith, Thomas. 1959. The Agrarian Origins of Modern Japan, Stanford: Stanford University Press.

Steinberg, Richard. 2002. In the Shadow of Law or Power? Consensus-Based Bargaining and Outcomes in the GATT/WTO. International Organization, 56, 339-374.

Steiner, Jürg and Dorff, Robert. 1980. Decision by Interpretation : A New Concept for an Often Overlooked Decision Mode. British Journal of Political Science, 10, 1-13. Terray, Emmanuel. 1987-1989. Un anthropologue africaniste devant la cité grecque. Opus. Rivista internazionale per la storia economica e sociale dell'antichità, VI-VIII, 1325.

Urfalino, Philippe. 2007, La décision par consensus apparent. Nature et propriétés. Revue Européenne des Sciences Sociales, 44, 136, p. 47-70.

Urfalino, Philippe. 2010. Deciding as Bringing Deliberation to a Close. Social Science Information, 49, 111-140. 
Urfalino, Philippe. 2012. Reasons and Preferences in Medicine Evaluation Committees. Pp.

173-203 in H. Landemore, J. Elster (eds), Collective Wisdom. Principles and

Mechanisms, Cambridge: Cambridge University Press.

Urfalino, Philippe and Vilkas, Catherine. 1995. La délégation du jugement esthétique. Les

Fonds Régionaux d'Art Contemporain. Paris: L’Harmattan.

Yngvesson, Barbara. 1978. Leadership and Consensus: Decision-Making in an Egalitarian

Community. Ethnos, 43, 73-90.

\footnotetext{
${ }^{1}$ The first versions of this text were discussed during the Workshop of Political Theory in the Political Sciences Department at Yale University in April 2011, and during the Workshop "Decision-Making by Consensus" in the Institute of Social Sciences at the Humbolt University in Berlin in October 2013. Thanks to Bryan Garsten, Hélène Landemore, Andrew March, Michael Morrel, Melissa Schwartzberg, Eva Krick and Tanja Pritzlaff for their useful comments. I am especially grateful to Stéphanie Novak, Gudrun Kristinsdottir and two anonymous referees for their critics of the penultimate version of this article.

${ }^{2}$ Baechler 1994, Silberbauer 1982.

${ }^{3}$ Mahé 2000, Abélès 1983, Mandela 1995, Terray 1988, Ferme 1998, Bailey 1965, Dumont 1981, Popkin 1979, Smith 1959.

${ }^{4}$ Polletta 2002. One finds on Internet, with the keyword "decision by consensus", many methodological guides in favor of this mode of decision; they come from the ecologist, feminist or civic rights movements in the 1970s.

${ }^{5}$ Haug 2010.

${ }^{6}$ Buzan 1981.

${ }^{7}$ Pasquino 2007, Graber 2007, Urfalino 2012.

${ }^{8}$ Cohen 1989, Fishkin 1991, Sen 2005.

${ }^{9}$ As has been the case in the assemblies of the M-15 movement in Madrid and other Spanish cities.

${ }^{10}$ As in the case of the Council of the European Union which articulates the rule of non-opposition and the qualified majority rule (Novak, 2013).

${ }^{11}$ El-Hakim 1978.

${ }^{12}$ Yngvesson 1978.

${ }^{13}$ Steiner and Dorff 1980.

${ }^{14}$ Steinberg 2002, p. 343-344.

${ }^{15}$ Urfalino 2012.

${ }^{16}$ I do not keep the designation 'decision by interpretation' proposed by Steiner and Dorff for another reason. It emphasizes the work of the chairman who figures out and summarizes the 'sense of the meeting'; this activity is very important and there is surely an art to do it well, but it does not point to the main characteristic of the mode of decision they describe: the absence of opposition as a stopping rule. Urfalino $(2007,2010,2012)$ has used the expression "apparent consensus", but it sounds too negative and it does not sufficiently emphasize the stopping rule. The expression
} 
decision or rule "by non-opposition", proposed by Jon Elster (2013, p. 35), is more descriptive and appropriate.

${ }^{17}$ I employ here the term « informal » in the sense of « without form ». The term is sometimes used in the sense of « unwritten ». There are of course unwritten rules, which is incidentally most often the case for the rule of non-opposition.

18 Urfalino and Vilkas 1995, p. 120-124.

${ }^{19}$ The use of non-opposition as a device accepted for procedural decisions, named General Consent, is evoked in the General Robert's Rules (Robert, 1847-1915, art. VIII, \46). It is also used as timesaving device in the Parliaments of Denmark, Norway, Spain, Sweden and the United Kingdom (Saalfeld, 1995, p. 532, the expression used is «Voting by assent »).

${ }^{20} \mathrm{I}$ have explained my conception of the collective decision rule as a stopping rule and their difference with voting in Urfalino, 2010, mainly p. 127-137.

${ }^{21}$ For another analysis of decision-making rules of committees in terms of normatively binding sequence of acts, close to ours but based on different theories, see Nullmeier and Pritzlaff 2009.

${ }^{22}$ Gross 1951.

${ }^{23}$ Until 1966, the non-permanent members were only 6 and the necessary qualified majority was 7 out of 11 (Cross, 1968). So the votes on Southern Rhodesia issue were for permanent members, 1 Yes, 0 No and 4 Abstain, and for non-permanent members, 6 Yes, 0 No and 0 Abstain, the whole result being 7 Yes, 0 No and 4 Abstain. The supermajority required was obtained, but the reality of "the concurring votes of permanent members" was, with one positive vote and four abstentions, a question of interpretation.

${ }^{24}$ This practice, which consists of considering that, in the use of the rule of unanimity, the abstention is not a veto, was already observable within the Society of the Nations. Thereafter, several European organizations (the European Economic Community, Euratom, the European Council, the European Free Trade Association) included this practice in their written rules (Fromont, 1961).

${ }^{25}$ It is what the first permanent representative says who abstained from voting at the Security Council, on April 29th, 1946, Mr. Gromyko, in the name of the U.S.S.R. said: « Bearing in mind (...) that my voting against the Australian draft resolution would make its adoption impossible, I shall abstain from voting » (Gross, 1951, p.216).

${ }^{26}$ Terray 1987-89.

${ }^{27}$ Ferme 1998.

${ }^{28}$ Polletta 2002, p. 8-9.

${ }^{29}$ Pasquino 2007.

${ }^{30}$ El Hakim 1978, Coleman 1990, p. 857-858.

${ }^{31}$ Steinberg 2002.

32 This is clearly explained in an article on the Convention on the Law of the Sea (Charney, 1978, p. 43).

${ }^{33}$ Terray 1987-89, p. 21.

${ }^{34}$ Poletta 2002, p. 194.

${ }^{35}$ Pasquino 2007, Urfalino 2012.

${ }^{36}$ His comments on Polish Liberum veto are very clear on this point (Rousseau, 2004, Sect. 9, p. 216219), see Schwartzberg 2008.

${ }^{37}$ Cohen 1989, Fishkin 1991, Sen 1999.

${ }^{38}$ Martin 1998, Sen, 1999.

${ }^{39}$ Mandela 1995, p. 20. 
${ }^{40}$ May 1952, Rae 1969.

${ }^{41}$ Terray 1987-89.

${ }^{42}$ Mandela 1995, p. 21.

${ }^{43}$ Urfalino 2012, p. 194.

${ }^{44}$ Thanks to a referee, I have discovered the important contribution of Jane Mansbridge (1980) to the study of decision by consensus, but too late to discuss it thoroughly here. However, I note that the contrast I point here converges with the one she makes between, on one hand, "unitary democracy", using consensus and concerning itself with equality of respect rather than with equality of influence and, on the other hand, "adversary democracy", using majority voting and concerning itself first and foremost with the equality of influence on the final decision. 